\title{
SYNTHESIS AND CHARACTERIZATION OF NEODYMIUM (III), SAMARIUM (III) AND TERBIUM (III) COMPLEXES CONTAINING BIS (SALICYLALDEHYDE) - ORTHOPHENYLENEDIAMINE AS LIGAND
}

\author{
Uwanta, Emaime. J. \\ ${ }^{1}$ Department of Chemistry, Faculty of Natural and Applied Sciences Akwa Ibom State University Ikot Akpaden, Akwa Ibom \\ State \\ Email: emaimeuwanta@gmail.com,
}

Ukoha, Pius. $O$.

${ }^{2}$ Department of Pure and Industrial Chemistry, Faculty of Physical Sciences, University of Nigeria, Nsukka, Enugu State, Nigeria.

Email: pius.ukoha@unn.edu.ng

Ekwere, Ifiok O.

Department of Chemistry, Akwa Ibom State University, Nigeria

Email: ifiokekwere@aksu.edu.ng

DOI: 10.31364/SCIRJ/v8.i6.2020.P0620XX

http://dx.doi.org/10.31364/SCIRJ/v8.i6.2020.P0620XX

\section{Abstract}

The solid complexes of neodymium (III), samarium (III) and terbium (III) were synthesized from a tetradentate Schiff base, bis(salicylaldehyde)orthophenylenediamine. The Schiff base ligand was prepared from condensation of o-phenylenediamine (1, 2diamine benzene) with salicylaldehyde. The prepared Schiff base reacts with Nd (III) to give a complex with stoichiometric ratio of (1:2) (metal: ligand) while Sm (III) and Tb (III) react to give complexes with stoichiometric ratio (1:1) (metal : ligand). The complexes have been characterized by elemental analysis, molar conductance, electronic absorption and infrared spectral studies. Possible structures were suggested for Nd(BSOPD)2 and SmBSOPD which were based on the results.

Keywords: Schiff Base, Metal Complexes, Stoichiometry, Complexation, Spectrophotometer.

\subsection{Introduction}

Schiff's bases are formed when either ammonia or primary amine reacts with a ketone or an aldehyde under proper conditions. They are weak bases and are readily hydrolysed by dilute mineral acids, but not by aqueous alkalis [1]. Schiff bases are important as ligands in metal coordination chemistry. The lanthanide form chemical bond with atoms belonging to the hard acid groups like oxygen to form Ln-O bonds. The coordination chemistry of lanthanide ions is rich in compounds where Ln ion has coordination numbers between 6 and 10 [2]. The large coordination numbers observed in the complexes of lanthanide are usually due to their predominantly ionic bonding nature [3]. Lanthanide metals and their compounds are distinctly unique due to their spectroscopic, physical and chemical characteristics. Lanthanide complexes have been successfully applied as diagnostic tools in biomedical analysis such as magnetic resonance imaging (MRI) contrast agents, catalysis, material sciences and nuclear power generation [4,5]. The lanthanide complexes have also been found to be useful in glass industries, television industry, metallurgical industries and in the making of strong magnets [6,7]. There are numerous literature on Schiff base - transition metal complexes [8,9], with scarce researches on the Schiff base complexation with lanthanide metals. Accordingly, this study utilizes lanthanide metals in the synthesis and characterization of neodymium (III), samarium (III) and terbium (III) complexes containing bis(salicylaldehyde)orthophenylenediamine as ligand. 


\subsection{Materials and Method}

All the reagents and solvents used were of analytical grade and were used as supplied unless otherwise stated. Dimethylformamide (DMF), ethanol, 1,2-dimethylbenzene, neodymium (III) nitrate. $6 \mathrm{H}_{2} 0$, samarium (III) chloride and terbium (III) chloride were purchased from Aldrich-Sigma company Ltd, Germany.

\section{Physical measurements}

The melting points of the ligand and complexes were determined using Electrothermal point apparatus The IR spectra were recorded using a KBr disc technique MB 3000 spectrophotometer (SHIMADZU) in the range of 400-4000 $\mathrm{cm}^{-1}$. The electronic spectra in the range 200-800 nm were obtained in DMF on a Shimadzu spectrophotometer. The molar conductivity of the ligands and the complexes were determined in DMF using WTW model LF 90 conductivity meter in the units of Scm ${ }^{2} \mathrm{~mol}^{-1}$. Micro analytical data were obtained on a LECO-CHN-932 analyzer at Campbell micro analytical laboratory, department of chemistry, University of Otago, New Zealand. The solubility of the ligand and the complexes in the various solvents were determined at room temperature.

\section{Synthesis of Schiff base-Bis(salicylaldehyde)orthophenylenediamine-BSOPD}

The Schiff base (BSOPD) was synthesized using 1, 2 diaminebenzene and salicylaldehyde as reactants, according to the method outlined by Jianning et al., Uddim and Salam [10,11] with some modifications.

$5.405 \mathrm{~g}$ (0.05 moles) of 1, 2- diaminobenzene (o-phenylenediamine) was dissolved in $50.0 \mathrm{~cm}^{3}$ of absolute ethanol. Thereafter 2.0 $\mathrm{cm}^{3}$ of $\mathrm{NaOH}(0.1 \mathrm{M})$ was added slowly, followed by $10.45 \mathrm{~cm}^{3}$ of salicylaldehyde $(12.22 \mathrm{~g}, 0.1 \mathrm{M})$. The final reaction mixture, yellow in colour was refluxed for $3 \mathrm{~h}$ at $55-60{ }^{\circ} \mathrm{C}$ and the precipitate formed was allowed to cool to room temperature. The clear supernatant was discarded, and then the precipitate was washed with cold ethanol in batch using $50 \mathrm{~cm}^{3}$ of the ethanol. The washed precipitate was recrystallized in ethanol, dried in the oven at a temperature of $50{ }^{\circ} \mathrm{C}$. The product, having an orange yellow colouration, was then dried in dessicator over calcium chloride.

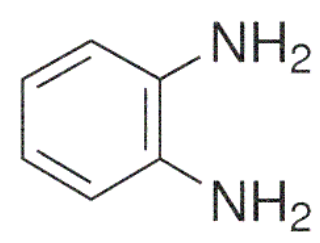

1, 2- diaminobenzene

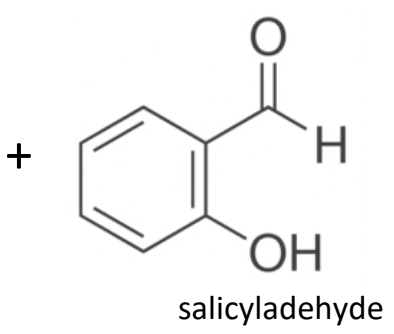

2,2'-((1E,1'E)-(1,2-phenylenebis(bis(azanylidene))bis(methanylylidene))diphenol (BSOPD)

Fig 1. Preparation of Schiff base ligand (BSOPD)

\section{Synthesis of Nd- BSOPD, Sm-BSOPD and Tb-BSOPD complexes}

The complexes of $\mathrm{Nd}$ (III), Sm (III) and $\mathrm{Tb}$ (III) were prepared by mixing requisite amount of the ligand with the metal salt to form a 1:2 (M:L) metal ligand ratio for $\mathrm{Nd}$ (III) and 1:1 for $\mathrm{Sm}(\mathrm{III})$ and $\mathrm{Tb}$ (III). The procedure involved adding an ethanolic solution $\left(10 \mathrm{~cm}^{3}\right)$ of the metal salt dropwisely to hot ethanolic solution of the ligand BSOPD $\left(30 \mathrm{~cm}^{3}\right)$. The resulting solution was refluxed for 4-6 h with an observable colour change [12] and volume of the solution was reduced to $15 \mathrm{~cm}^{3}$. The resulting solution was allowed to stand in an ice bath over night; the solid complex compound synthesized was filtered, washed thoroughly with successive portions of ethanol followed by diethyl ether. It was then dried in a dessicator over calcium chloride..

\subsection{Results and Discussion}

The physical characteristics, micro analytical and molar conductivity data of the ligand and its $\mathrm{Nd}(\mathrm{III}), \mathrm{Sm}(\mathrm{III})$ and $\mathrm{Tb}$ (III) complexes are given in Table 1. The synthesized complexes are stable at room temperature in the solid state. The metal complexes are soluble in DMF and DMSO while insoluble in common organic solvents. The observed values of molar conductivity of the complexes show that they are non electrolytes. The complexes were characterized using the following physical studies. 
Table 1: Physical and Analytical data of BSOPD, Nd (III) and Sm (III) Complexes

\begin{tabular}{|c|c|c|c|c|c|c|c|c|c|}
\hline Compound & F.W & Yield\% & $\begin{array}{l}\text { M:L } \\
\text { ratio }\end{array}$ & $\mathrm{MP}^{0} \mathrm{C}$ & Colour & $\begin{array}{l}\text { Molar } \\
\text { conductiv } \\
\text { ity } \\
\text { Scm }^{2} \mathrm{~mol}^{-1}\end{array}$ & $\begin{array}{l}\text { C\% calc. } \\
\text { (found) }\end{array}$ & $\begin{array}{l}\text { H\% } \\
\text { calc. } \\
\text { (found) }\end{array}$ & $\begin{array}{l}\text { N\% } \\
\text { calc. } \\
\text { (found) }\end{array}$ \\
\hline BSOPD & 316.36 & 77.34 & & $158-160$ & $\begin{array}{l}\text { orange } \\
\text { yellow }\end{array}$ & 2.56 & $\begin{array}{l}75.93 \\
(75.97)\end{array}$ & $\begin{array}{l}5.10 \\
(5.06)\end{array}$ & $\begin{array}{l}8.85 \\
(8.91)\end{array}$ \\
\hline Nd-BSOPD & 836.95 & 60.00 & $1: 2$ & $150-152$ & Green & 21.97 & $\begin{array}{l}57.40 \\
(57.48)\end{array}$ & $\begin{array}{l}3.61 \\
(4.31)\end{array}$ & $\begin{array}{l}8.37 \\
(8.84)\end{array}$ \\
\hline Sm-BSOPD & 681.16 & 62.00 & $1: 1$ & $140-142$ & $\begin{array}{l}\text { Light } \\
\text { brown }\end{array}$ & 33.23 & $\begin{array}{l}35.27 \\
(35.95)\end{array}$ & $\begin{array}{l}4.14 \\
(4.12)\end{array}$ & $\begin{array}{l}4.11 \\
(4.41)\end{array}$ \\
\hline Tb-BSOPD & 684.73 & 61.80 & $1: 1$ & 200 & Brown & 57.46 & $\begin{array}{l}35.08 \\
(34.14)\end{array}$ & $\begin{array}{l}4.12 \\
(4.01)\end{array}$ & $\begin{array}{l}4.09 \\
(4.39)\end{array}$ \\
\hline
\end{tabular}

The synthesized complexes gave a sharp melting point indicating the isolation of fairly pure compounds. The micro-elemental analysis for $\mathrm{C}, \mathrm{H}$ and $\mathrm{N}$, as well as the molecular weight of the complexes obtained were in agreement with the predicted formula for complexes. The study showed that the metal to ligand, ratio was 1:2 for Nd-BSOPD, 1:1 for Sm-BSOPD and Tb-BSOPD. An outline of the proposed structure for the synthesized complexes and ligand, BSOPD is depicted in Fig. 2. The melting point, elemental analysis, percentage yield and formula weight data are given in Table 1, which indicates the molecular formula of the complexes as follows; Nd-BSOPD $\left(\mathrm{C}_{40} \mathrm{H}_{30} \mathrm{~N}_{5} \mathrm{O}_{7} \mathrm{Nd}\right)$, Sm-BSOPD $\quad\left(\mathrm{C}_{20} \mathrm{H}_{16} \mathrm{~N}_{2} \mathrm{O}_{2} \mathrm{Cl}_{3} \mathrm{Sm} .6 \mathrm{H}_{2} \mathrm{O}\right)$ and Tb-BSOPD $\left(\mathrm{C}_{20} \mathrm{H}_{16} \mathrm{~N}_{2} \mathrm{O}_{2} \mathrm{Cl}_{3} \mathrm{~Tb} .6 \mathrm{H}_{2} \mathrm{O}\right)$<smiles>Oc1ccccc1/C=N/c1ccccc1/N=C/c1ccccc1O</smiles>
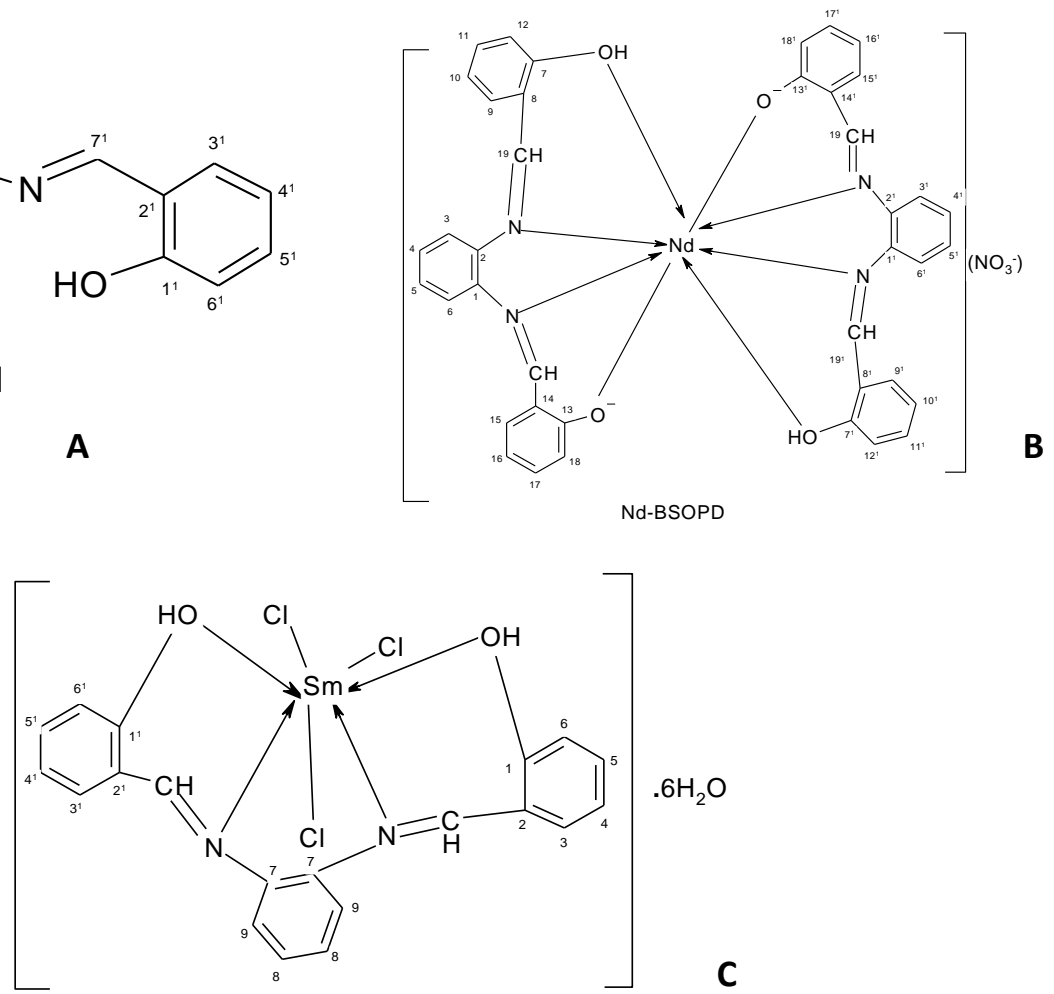

Sm-BSOPD

Fig. 2 (A) Structure of the ligand: 2,2'-((1E,1'E)-(1,2-phenylenebis(bis(azanylidene))bis(methanylyli dene))diphenol - BSOPD (B) Proposed structure of Nd-BSOPD (C) Proposed structure of Sm-BSOPD

\section{Infrared Spectral studies}

The infrared spectra data of the prepared ligand and its complexes are listed in Table 2. The IR spectrum of BSOPD was compared with those of the $\mathrm{Nd}, \mathrm{Sm}$ and $\mathrm{Tb}$ complexes to determine the coordination sites. There are some guiding peaks that are expected to be involved in chelation. The IR spectrum of the ligand BSOPD showed a strong band centered at $3456 \mathrm{~cm}^{-1} \mathrm{due}$ to $\mathrm{v}$ 
(O-H) of phenols. In the spectra of Nd (III), Sm (III) and Tb (III) complexes, the band became broad and occurred at 3342,3412 and $3404 \mathrm{~cm}^{-1}$, respectively. The IR spectrum of BSOPD showed a strong band at $1616 \mathrm{~cm}^{-1}$ attributed to $\mathrm{v}(\mathrm{C}=\mathrm{N})$ of azomethine. This band is shifted to higher wave number in the complexes, indicating that the nitrogen is involved in cheletion. This is supported by bands appearing at 426, 405 and $441 \mathrm{~cm}^{-1}$ in $\mathrm{Nd}$ (III), Sm (III) and Tb (III), respectively, assigned to ${ }_{\mathrm{v}}(\mathrm{Ln}-\mathrm{N})$ $[13,14,15]$.

The ${ }_{v}(\mathrm{C}-\mathrm{OH})$ is observed at $1282 \mathrm{~cm}^{-1}$ in BSOPD while in the $\mathrm{Nd}$ (III), Sm (III) and Tb (III) complexes this band appeared at a lower wave number (difference of 31-39 $\mathrm{cm}^{-1}$ ). This suggests that BSOPD binds to ligand ions through the phenolic oxygen. This is confirmed by the presence of bands around $624-649 \mathrm{~cm}^{-1}$ in the complexes assigned to Ln-O [15]. The spectra also reveals an absorption band of $548 \mathrm{~cm}^{-1}$ in $\mathrm{Sm}(\mathrm{III})$ and $\mathrm{Tb}(\mathrm{III})$ complexes which correspond to Ln-Cl group.

Table 2: IR Data of ligand and its Complexes

\begin{tabular}{|l|c|c|c|c|c|c|c|c|c|}
\hline Compound & $\mathbf{v}(\mathbf{O}-\mathbf{H})$ & $\mathrm{v}(\mathbf{C}=\mathbf{N})$ & $\begin{array}{l}\mathrm{v}(\mathbf{C}=\mathbf{C}) \\
\text { aromat. }\end{array}$ & $\begin{array}{l}\mathrm{v}(\mathbf{C}-\mathbf{O H}) \\
\text { phenol }\end{array}$ & $\begin{array}{l}\mathrm{v}(\mathbf{C}-\mathbf{O}) \\
\text { phenol }\end{array}$ & $\begin{array}{l}\mathrm{v}(\mathbf{C}-\mathbf{H}) \\
\text { out of } \\
\text { plane C- } \\
\text { H bend }\end{array}$ & Ln-N & Ln-O & Ln-Cl \\
\hline BSOPD & $3456 \mathrm{~s}$ & $1616 \mathrm{~s}$ & $1483 \mathrm{~m}$ & $1282 \mathrm{~s}$ & $1192 \mathrm{~s}$ & $910 \mathrm{~s}$ & - & - & - \\
\hline Nd-BSOPD & $3342 \mathrm{br}$ & $1612 \mathrm{~m}$ & $1458 \mathrm{~m}$ & $1251 \mathrm{w}$ & $1153 \mathrm{~m}$ & $910 \mathrm{w}$ & $426 \mathrm{~m}$ & $649 \mathrm{w}$ & - \\
\hline Sm-BSOPD & $3412 \mathrm{br}$ & $1626 \mathrm{~m}$ & $1458 \mathrm{~m}$ & $1248 \mathrm{~m}$ & $1153 \mathrm{~m}$ & $916 \mathrm{~m}$ & $405 \mathrm{w}$ & $624 \mathrm{w}$ & $548 \mathrm{~m}$ \\
\hline Tb-BSOPD & $3404 \mathrm{br}$ & $1624 \mathrm{~s}$ & $1458 \mathrm{~m}$ & $1248 \mathrm{~m}$ & $1153 \mathrm{~m}$ & $919 \mathrm{w}$ & $441 \mathrm{~m}$ & $622 \mathrm{w}$ & $548 \mathrm{~m}$ \\
\hline
\end{tabular}

$\mathrm{s}$ - strong; $\mathrm{m}$ - medium; br - broad; $\mathrm{w}$ - weak

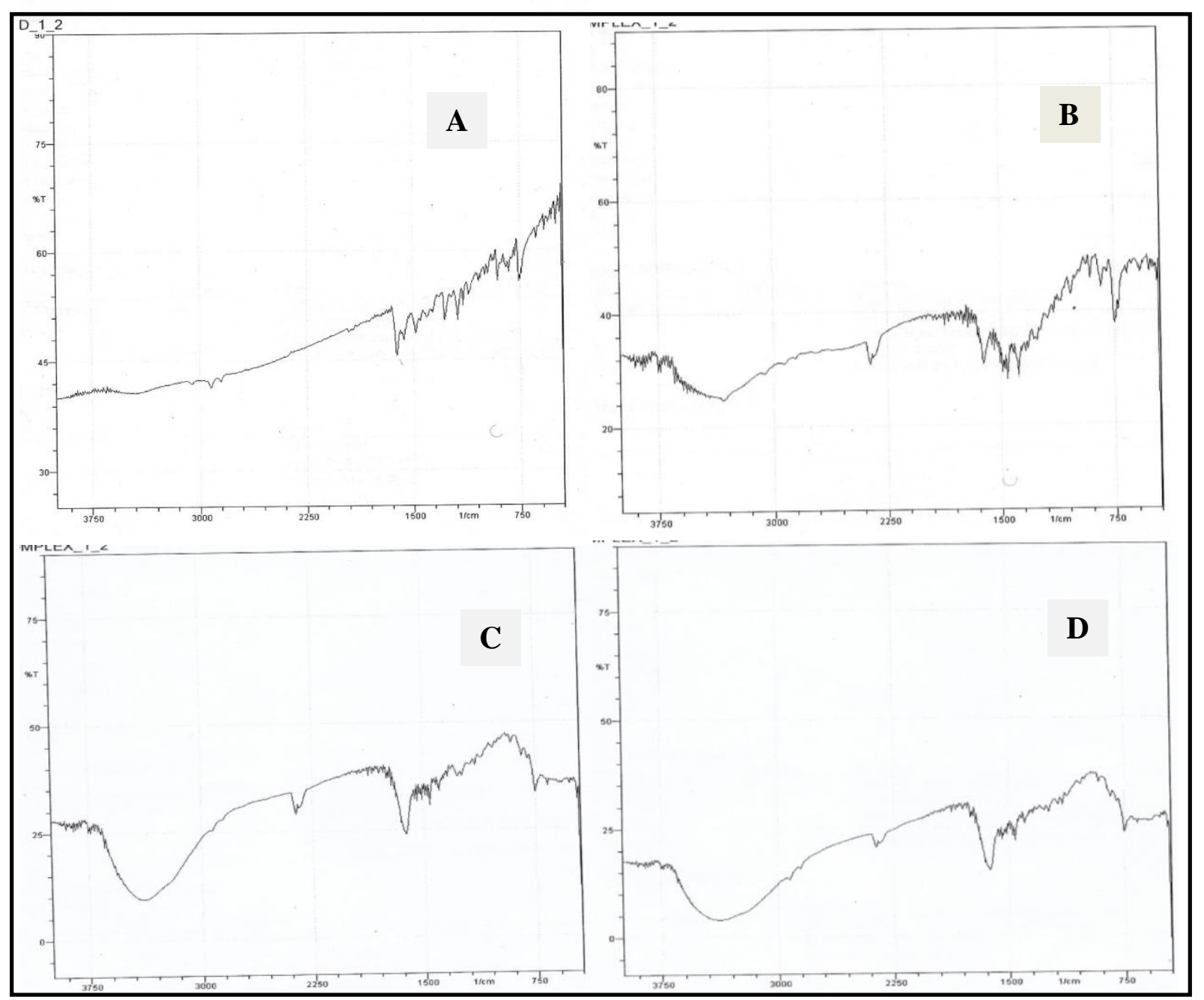

Fig. 3 FTIR Spectrum of (A) BSOPD, (B) Nd-BSOPD, (C) Sm-BSOPD, (D) Tb-BSOPD 


\section{Electronic spectra}

The electronic spectra of the ligand and complexes are shown in Fig 4. The ultraviolet visible electronic spectrum of the ligand, BSOPD and the complexes (Nd-BSOPD, Sm-BSOPD and Tb-BSOPD) are given in Table 3. The position of the bands vary depending on the compound under investigation; generally, the electronic transitions in the compounds correspond to the $\mathrm{n}-\pi^{*}$ and $\pi-\pi^{*}$ transitions.

Table 3 Electronic spectral data of $\mathrm{HL}$ and $\mathrm{Nd}$ (III), Sm (III) and $\mathrm{Tb}$ (III) complexes

\begin{tabular}{lll}
\hline Compounds & Absorption bands, $\mathbf{n m}\left(\mathbf{c m}^{-\mathbf{1}}\right)$ & Assigned transitions \\
\hline BSOPD & $333(30030), 272(36630)$ & $\mathrm{n}-\pi^{*}, \pi_{-} \pi^{*}$ \\
Nd-BSOPD & $376(26595.7), 332(30120), 318(31446.5)$ & $\mathrm{n}-\pi^{*}, \pi^{*} \pi^{*}$ \\
Sm-BSOPD & $384(26041.7)$ & $\mathrm{n}-\pi^{*}$ \\
Tb-BSOPD & $380(26315.8)$ & $\mathrm{n}-\pi^{*}$ \\
\hline
\end{tabular}

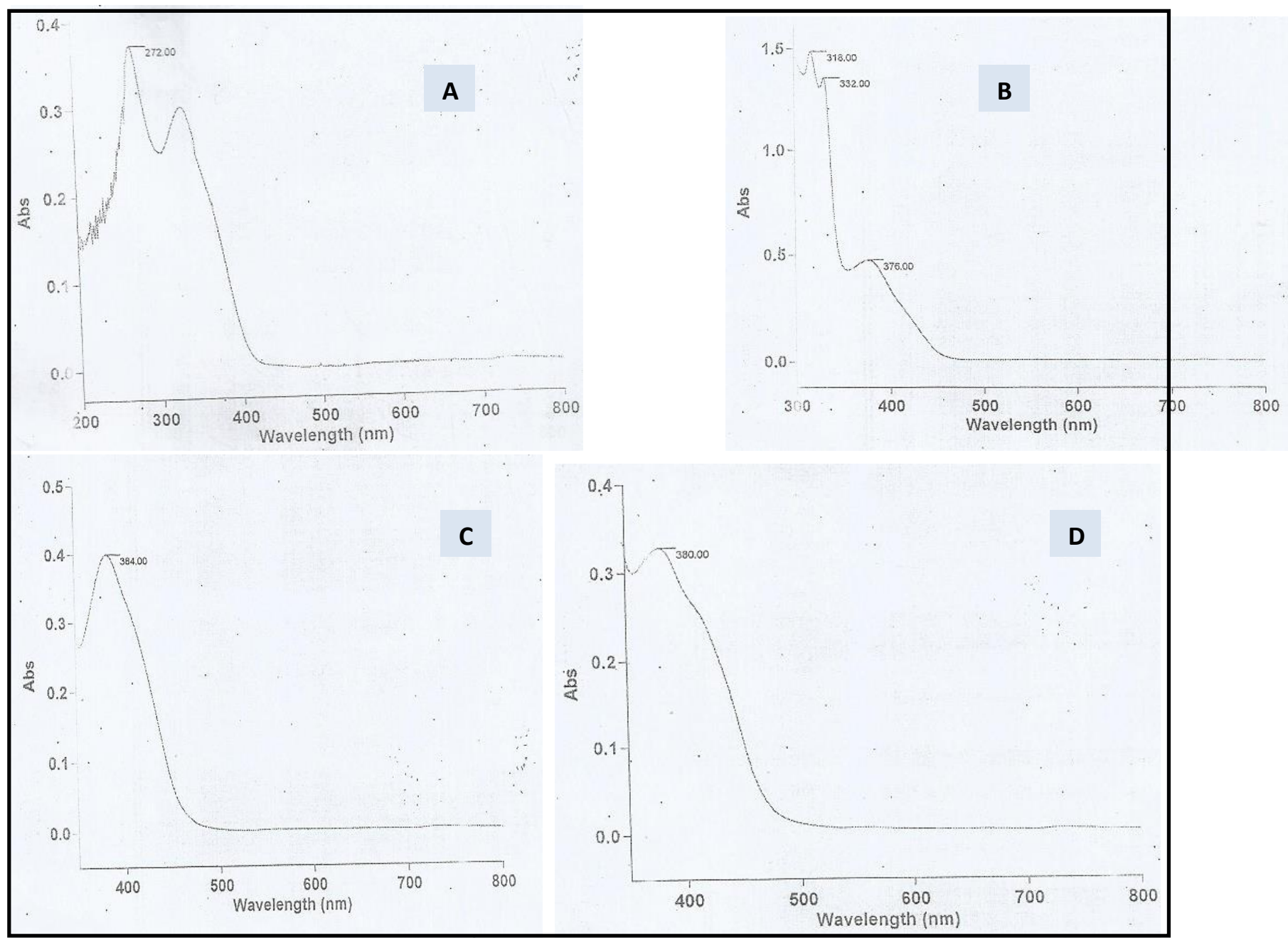

Fig. 4 UV-Visible Spectrum of (A) BSOPD (B) Nd- BSOPD (C) Sm-BSOPD (D) Tb-BSOPD

The electronic spectrum of the ligand, BSOPD, shows the $\mathrm{n}-\pi^{*}$ transition at $333 \mathrm{~nm}$ and the $\pi-\pi^{*}$ transition at $272 \mathrm{~nm}$. The complexes show band in the region of $n-\pi^{*}$ at $376 \mathrm{~nm}$ and $\pi-\pi^{*}$ at $318 \mathrm{~nm}$ regions for Nd-BSOPD. The Sm-BSOPD and TbBSOPD show $\mathrm{n}-\pi^{*}$ at $384 \mathrm{~nm}$ and $380 \mathrm{~nm}$, respectively. The variation in the values of $\lambda_{\max }$ with the ligands indicates the formation of the metal-ligand complexes. The lanthanide (III) complex has no significant absorption in the visible region (d-d transition), which is attributed to the fact that the $4 \mathrm{f}$ orbitals are effectively shielded; hence the electrons are not available for bonding. 


\subsection{Conclusion}

The Schiff base (BSOPD) was successfully prepared and used to synthesize new metal complexes of $\mathrm{Nd}(\mathrm{III}), \mathrm{Sm}(\mathrm{III})$ and $\mathrm{Tb}(\mathrm{III})$; the complexes have been characterized by physical methods and spectroscopic techniques. The molecular formular for NdBSOPD has been proposed as $\mathrm{C}_{40} \mathrm{H}_{30} \mathrm{~N}_{5} \mathrm{O}_{7} \mathrm{Nd}$, Sm-BSOPD $\left(\mathrm{C}_{20} \mathrm{H}_{16} \mathrm{~N}_{2} \mathrm{O}_{2} \mathrm{Cl}_{3} \mathrm{Sm} .6 \mathrm{H}_{2} \mathrm{O}\right)$ and Tb-BSOPD $\left(\mathrm{C}_{20} \mathrm{H}_{16} \mathrm{~N}_{2} \mathrm{O}_{2} \mathrm{Cl}_{3} \mathrm{~Tb} .6 \mathrm{H}_{2} \mathrm{O}\right)$. Based on the spectral study, the proposed structures of the complexes are depicted in fig. 2, where Nd-BSOPD shows an octahedral geometry.

\section{Acknowledgement}

The authors are grateful to the Department of Pure and Industrial Chemistry, Faculty of Physical Sciences, University of Nigeria, Nsukka for allowing the use of their laboratory facilities.

\section{References}

1. S.Q. Memon; N. Memon; A. Mallah; A. Soomoro and M. Y. Khuhawar (2014). Schiff Bases as chelating Reagents for Metal ions Analysis. Current Analytical Chemistry 10, 393-417.

2. C.H. Haung. (2010). Rare Earth Coordination. Foundations and Applications, Wiley Blackwell, Oxford.

3. K. Masatoshi, K.Igarashi, K.. Sato, K..Yoshihiro and M. Goto. (2011) Synthesis, characterization and emission properties of yttrium (III) and europium (III) complexes of a tripodal heptadentate Schiff base ligand $\mathrm{N}\left[\mathrm{CH}_{2} \mathrm{CH}_{2} \mathrm{~N}=\mathrm{CH}(2-\mathrm{OH}-3-\right.$ $\left.\left.\mathrm{MeC}_{6} \mathrm{H}_{3}\right)\right]_{3}$. Inorganic chimica acta, 367, 225-229.

4. S. Aime; S.G.Crich; E. Gianolio; G.B. Giovenzana; L.Tei and E. Terreno (2006). High sensitivity lanthanide (III) based probes for MR-medical imaging. Coordination Chemistry Reviews, vol., 250 no 11-12, pp1562-1579.

5. E.Kahn; C. Tessier; G. Lizard; A. Petiet; J.C Bernengo; J.R. Jourdan; E.Delain; F.Guiraud-Vitaux; N.Colas-Linhart; N.Siave; C.A. Cuenod; G.Frija and A.Todd-Pokropek (2014) .Distribution of MRI contrast agents in the livers of small animals by means of complementary microscopies. Cytometry, A51, 97-106

6. I. McGill (2005). 'Rare Earth Elements' Ullmanns Encyclopedia of Industrial Chemistry, (31) Weinheim. Wiley-VCH, p191.

7. R.Livergood (2010). Rare Earth Elements: A Wrench in the Supply Chain (PDF). Center for Strategic and International Studies.

8. N. Raman, Y.Pitchaikani Raja and A. Kulandaisamy (2001). Synthesis and Characterization of Cu(II), Ni(II), Mn(II), Zn(II) and VO(II) Schiff base complexes derived from o-phenylenediamine and acetoacetanilide, Proc. Indian, Acad. Sci.(Chem. Sci.),113(3), 183-189.

9. T. U. Dharmarajan, M. J.Smith, K. Kustin (2007). Synthesis and evaluation of tetraazamacrocyclic Schiff base of Chromium(III) ion and various metal complexes. Transition Metal Chemistry, Vol. 2400-2800: 13-17.

10. U.U. Jianning,. B. Zhang, W. U. Bowan, K. Zhang and H.U. Shenii (2007). The direct electrochemical synthesisof Ti(II), $\mathrm{Fe}(\mathrm{II}), \mathrm{Co}(\mathrm{II}), \mathrm{Sn}(\mathrm{II})$ and $\mathrm{Pb}(\mathrm{II})$ complexes with n,n, bis (salicylaldehyde) o-phenylenediamine. Turk J. Chem, 31 623-629.

11. M .N.Uddinn and M.A. Salam (2014) Bis(salicylaldehyde)phenylenediamine-a noble reagent for the determination of metal ions in environment. Research 1: 777

12. J. Liu., B. Zhan,. B.Wu and S. Hu.(2007). The direct electrochemical synthesis of Ti(II0, Fe(II), Cd(II), Sn(II) and Pb(II) complexes with N'-bis(salicylidene)-o-phenylenediamine. Turk. J Chem.31:623-629.

13. D. Harris (2010). Quantitative Chemical Analysis, 8th ed. W.H. Freeman and Company, NY.

14. K. Arora, M. Sharma and K.P. Sharma. (2009). Studies of some lanthanide(III) nitrate complexes of Schiff base ligands. Coden Ecjhao E-journal of Chemistry 6 (81), S201-S210

15. A.I .El-Ansary and Abdel-Kader (2012). Synthesis, characterization of La(III), Nd(III) and Er(III) complexes with Schiff bases derivrd from benzopyran-4-one and their florescence study. Int Jour. of Inorganic Chemistry, vol 2012. Article ID 90141513 pages doi:10. 1155/2012/901415. 